\title{
Correction to: Spatiotemporal Analysis of Tropical Cyclone Landfalls in Northern Bay of Bengal, India and Bangladesh
}

\section{Sunando Bandyopadhyay ${ }^{1} \cdot$ Susmita Dasgupta ${ }^{2} \cdot$ Zahirul Huque Khan $^{3} \cdot$ David Wheeler $^{4}$}

Published online: 28 May 2021

(C) Korean Meteorological Society and Springer Nature B.V. 2021

Correction to: Asia-Pacific Journal of Atmospheric Sciences. https://doi.org/10.1007/s13143-021-00227-4

Due to an unfortunate oversight during the correction process the images have not been updated. They should be:

The online version of the original article can be found at https://doi.org/ 10.1007/s13143-021-00227-4

\section{Sunando Bandyopadhyay}

sunando@live.com

Susmita Dasgupta

sdasgupta@worldbank.org

Zahirul Huque Khan zhk@iwmbd.org

David Wheeler

wheelrdr@gmail.com

1 Department of Geography, University of Calcutta, Kolkata 700019, India

2 Development Research Group, World Bank, Washington, DC 20433, USA

3 Institute of Water Modelling, Dhaka 1206, Bangladesh

4 World Resources Institute, Washington, DC 20002, USA 
Figure 1 Cyclonic storms (wind speed $\geq 34 \mathrm{kn}$ or $62 \mathrm{~km} / \mathrm{h}$ ) occurring in (a) the Northern Indian Ocean basin and landfalling in (b) the OdishaWest Bengal-Bangladesh (Northern Bay of Bengal) coast during 1877-2016. The coastline used for storm landfall analysis is shown in orange. Storm track data from: IBTrACS, IMD
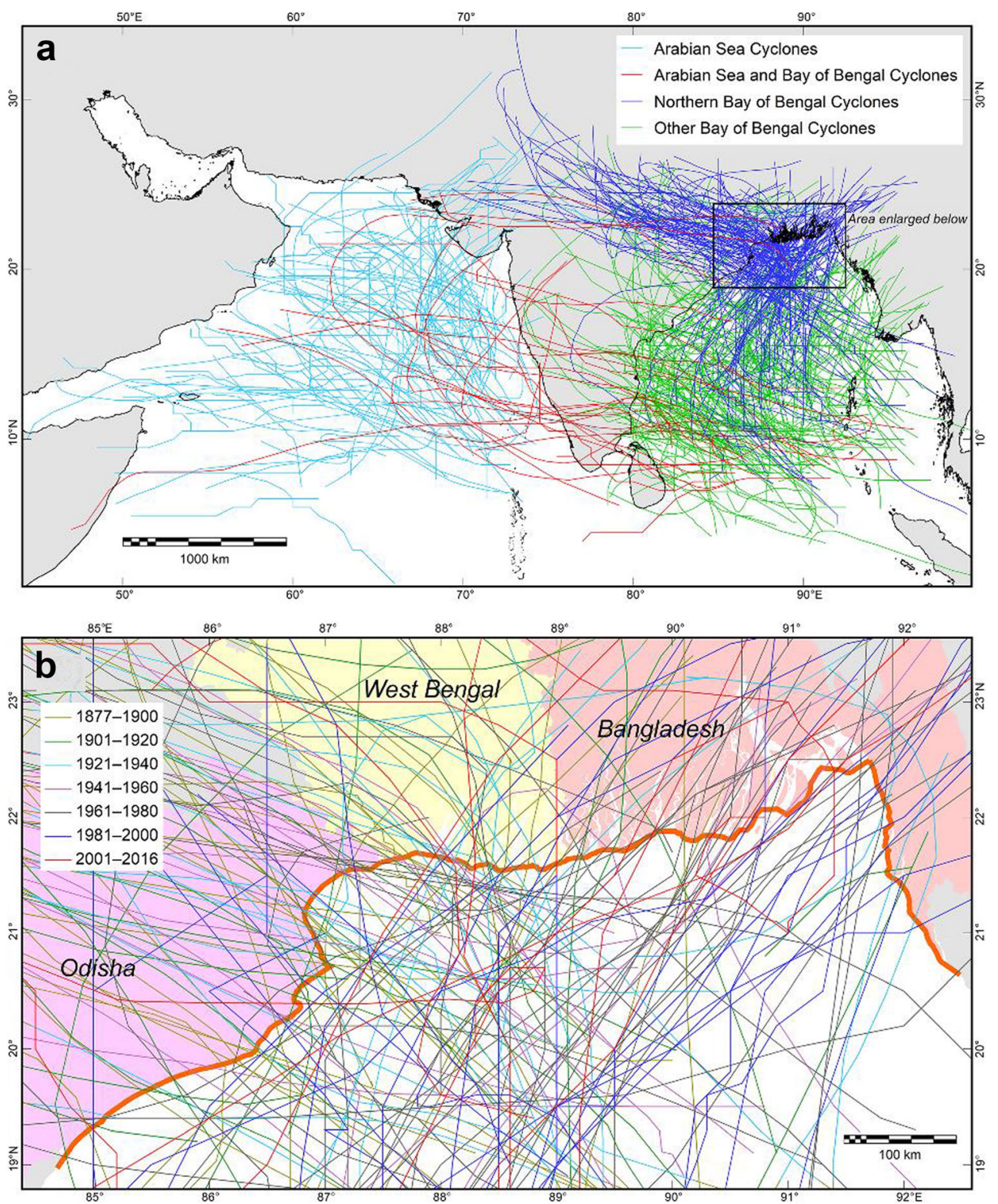

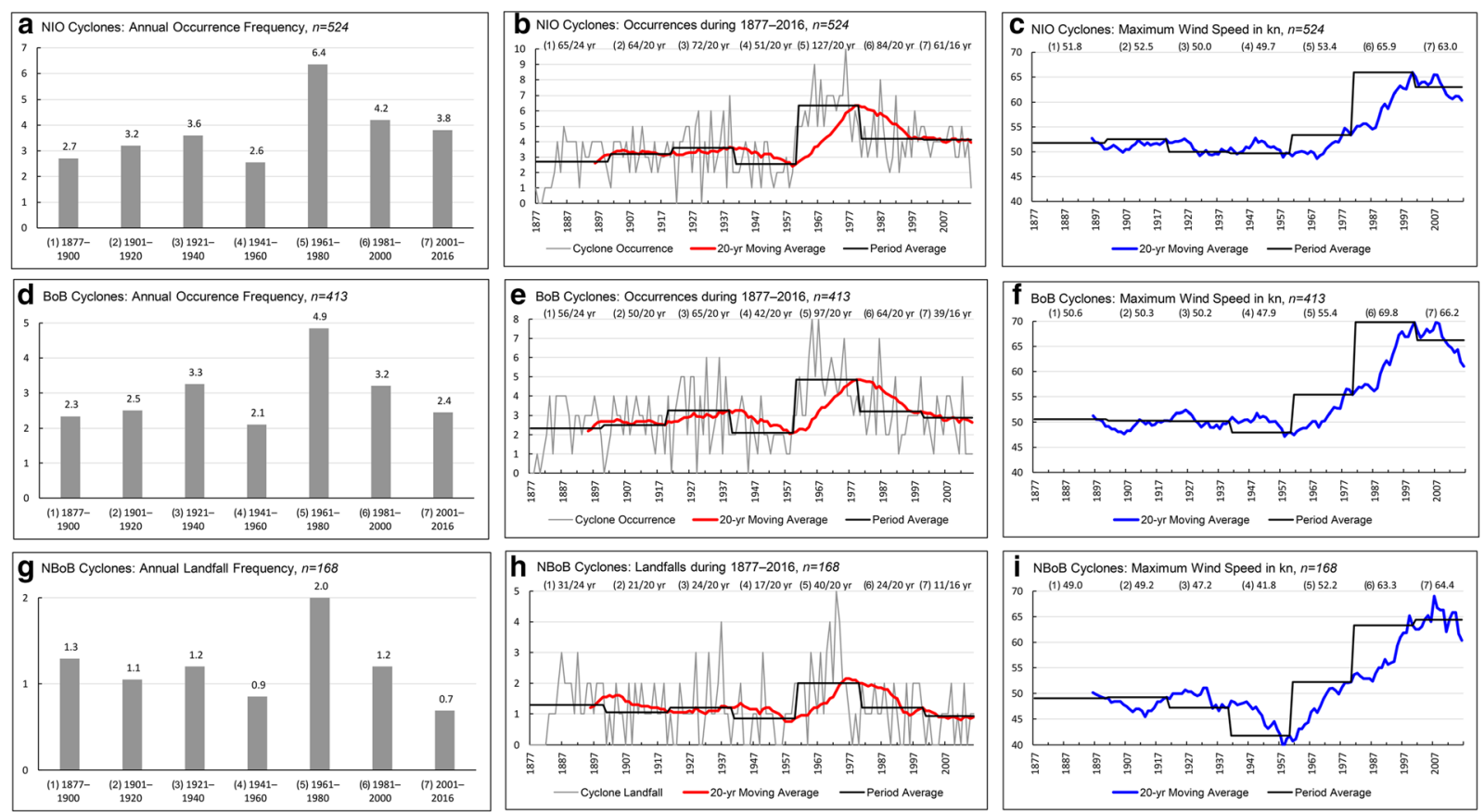

Figure 2 Storm occurrence / landfall and maximum wind speed characteristics of the cyclones occurring in the hierarchically smaller basins of Northern Indian Ocean $(\mathbf{a}-\mathbf{c})$, Bay of Bengal $(\mathbf{d}-\mathbf{f})$, and Northern Bay of Bengal, comprising Odisha, West Bengal and Bangladesh coasts $(\mathbf{g}-\mathbf{i})$,

during 1877-2016. Periods (1-7) are defined in lower axes annotations of the left panel charts. Note region-wise differences in vertical scales in the figures of the left and central panels. Data source: IBTrACS, IMD 

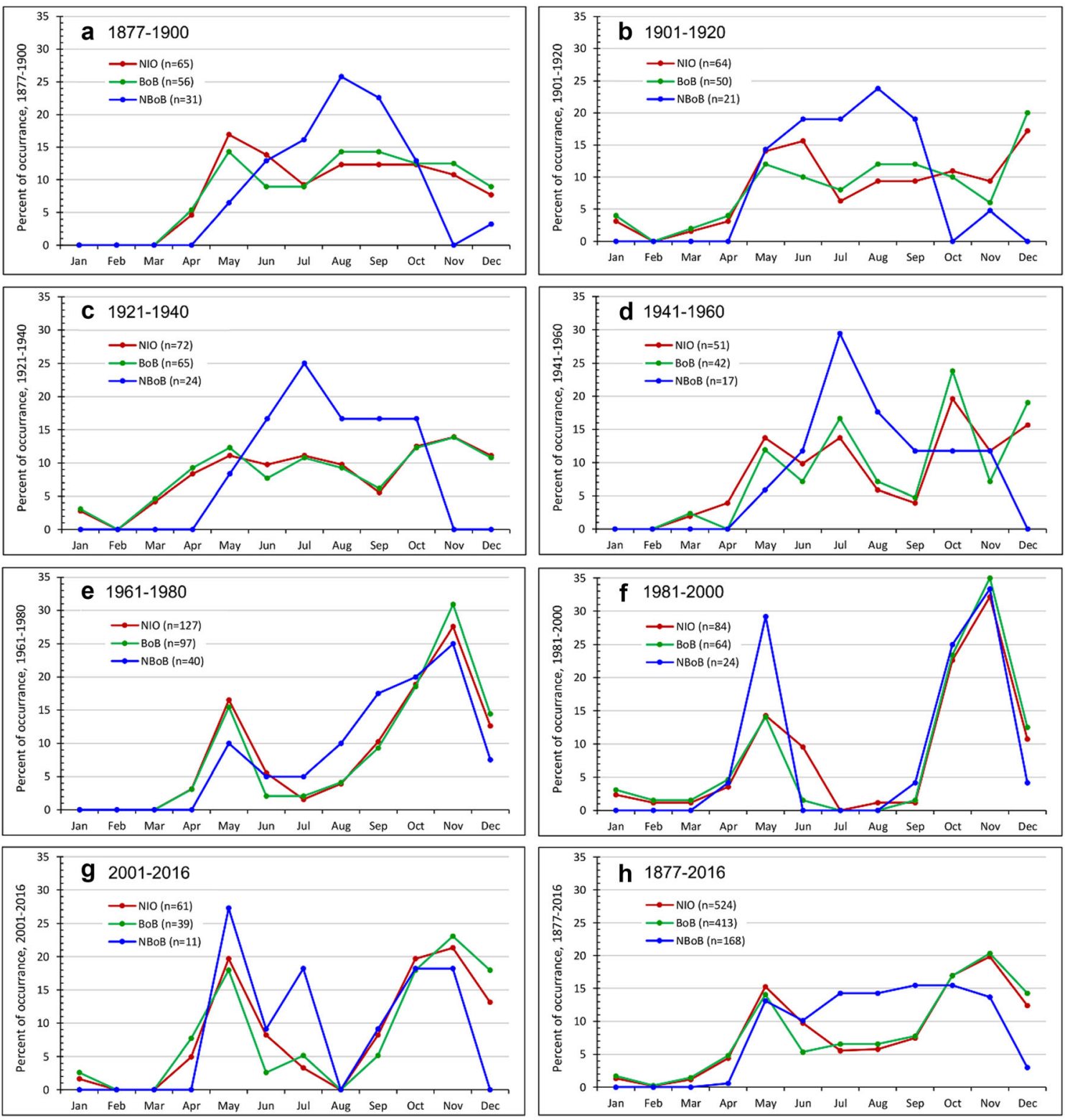

Figure 3 Regional and seasonal variation in occurrence of cyclonic storms in Northern Indian Ocean (NIO), Bay of Bengal (BoB), and landfall in Northern Bay of Bengal (NBoB) during 1877-2016. (a-

g) show the percentage of all storm crossings for each of the seven time periods; (h) considers storms of the entire span of study. Data source: IBTrACS, IMD 


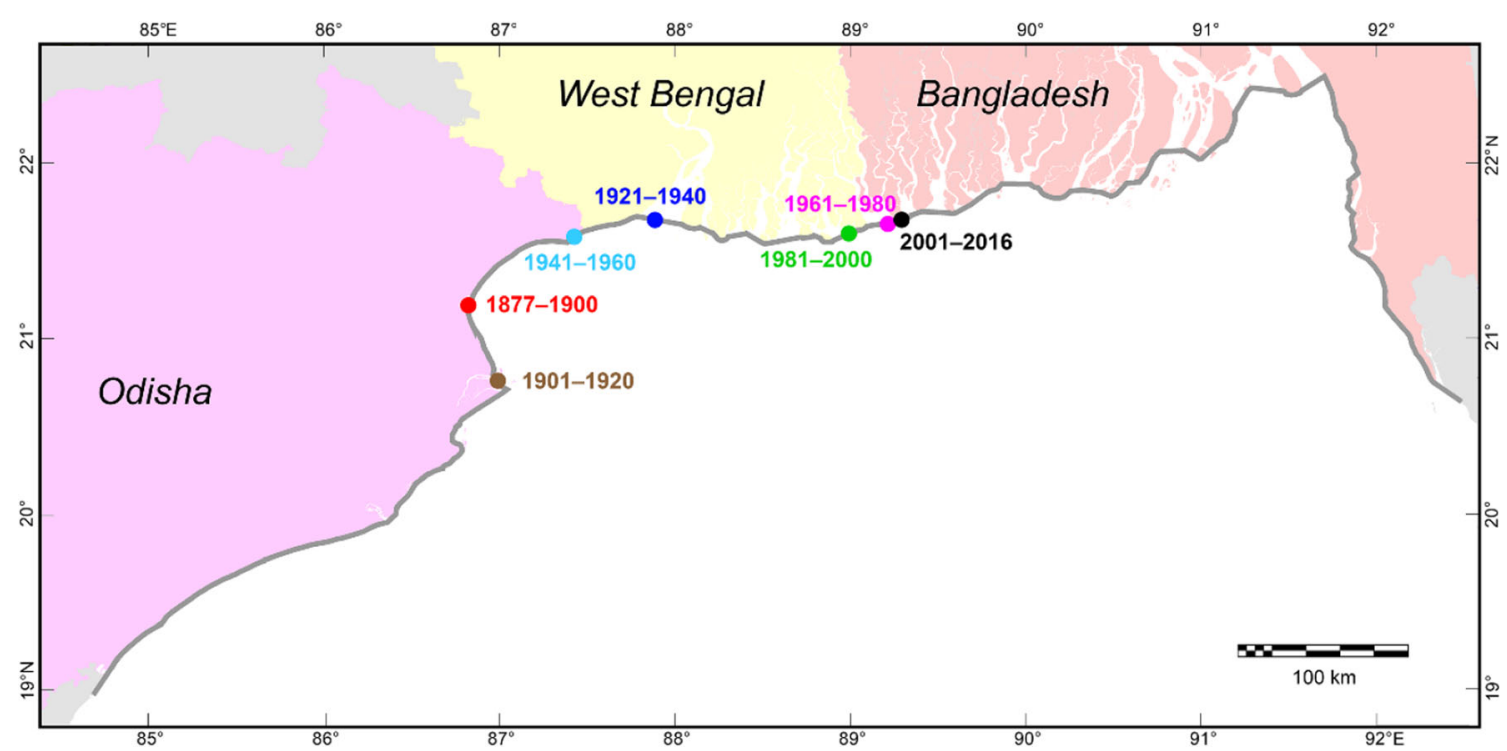

Figure 4 Storm landfalls in the Northern Bay of Bengal coast: Median locations of 168 storms by period, composite for 1877-2016. Data source: IBTrACS, IMD

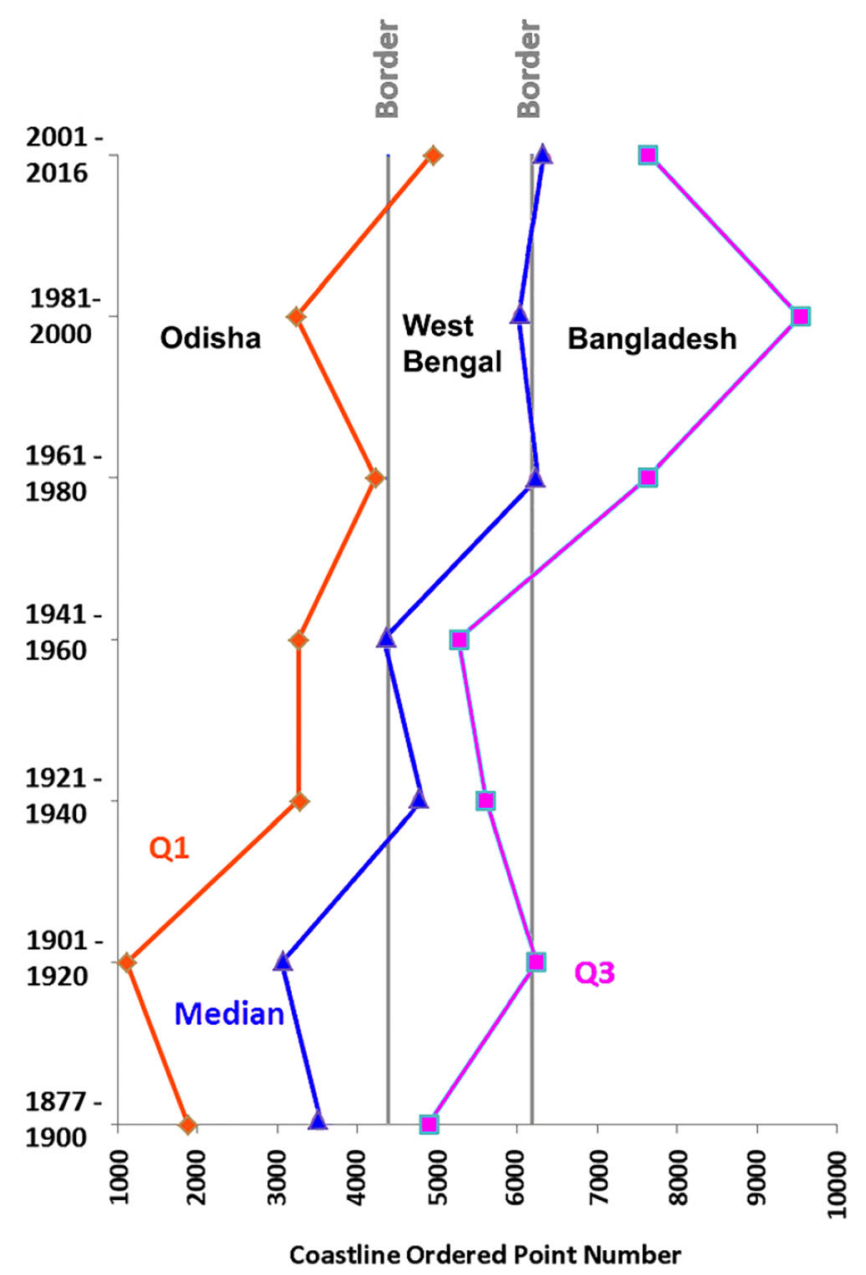

Figure 5 Storm landfalls in the Northern Bay of Bengal coast: Distribution by seven periods between 1877 and 2016. Q1 and Q3 stand for first quartile and third quartile, respectively. Data Source: IBTrACS, IMD 


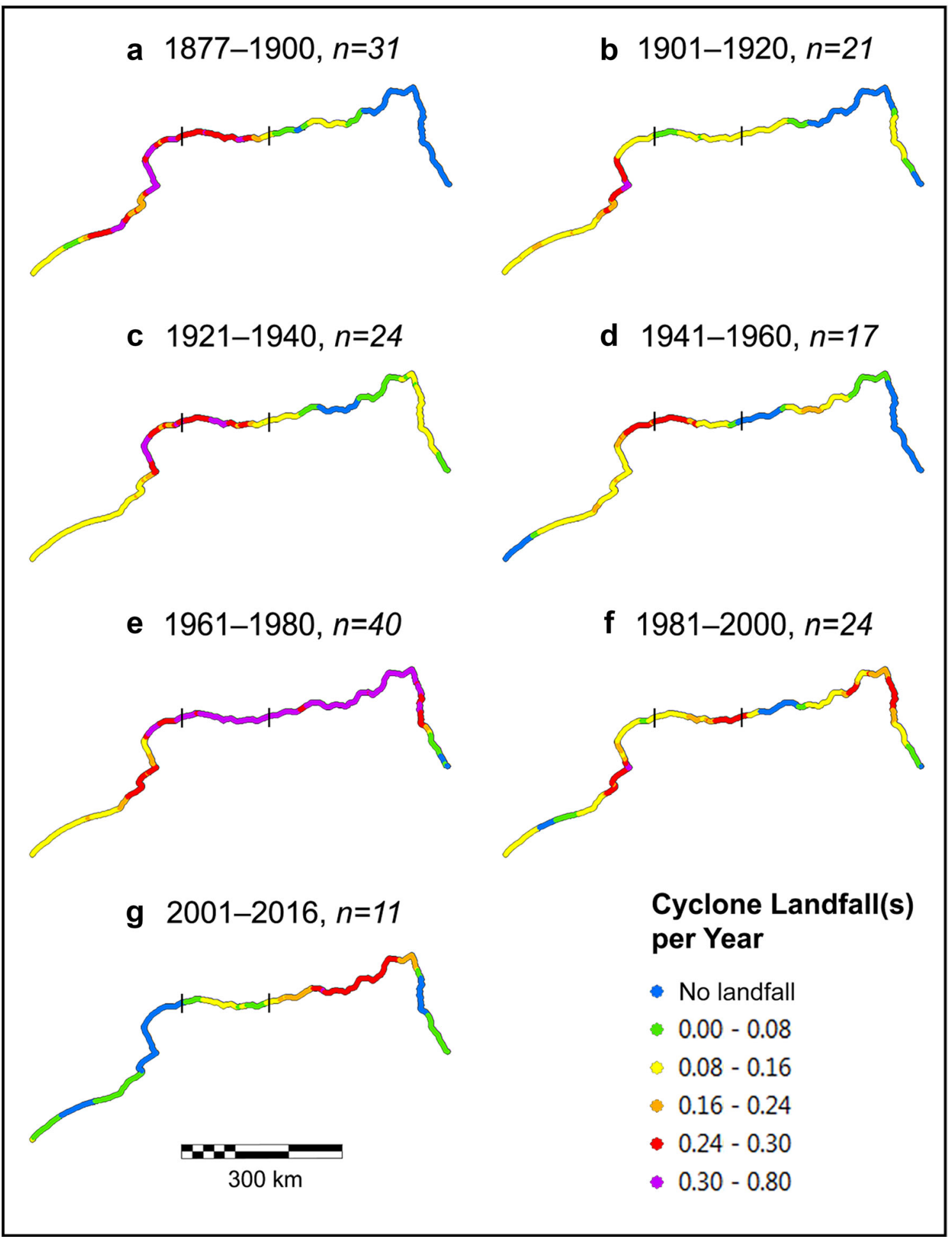

Figure 6 Cyclone landfall intensities (strikes/year) in Northern Bay of Bengal coasts: shown by periods (a-g). Data source: IBTrACS, IMD 


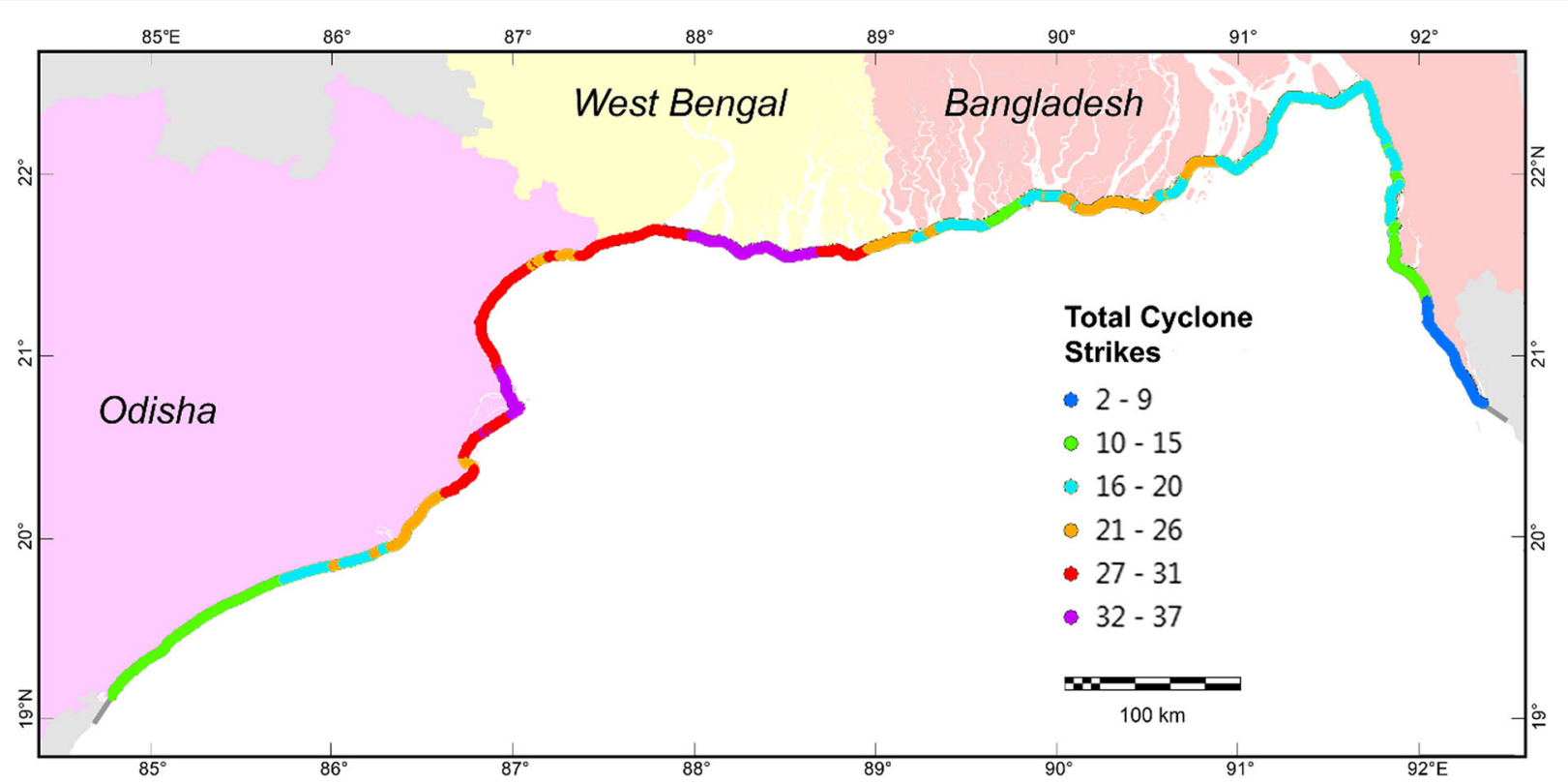

Figure 7 Cyclone landfalls in the Northern Bay of Bengal coast, composite for 1877-2016. Data source: IBTrACS, IMD 


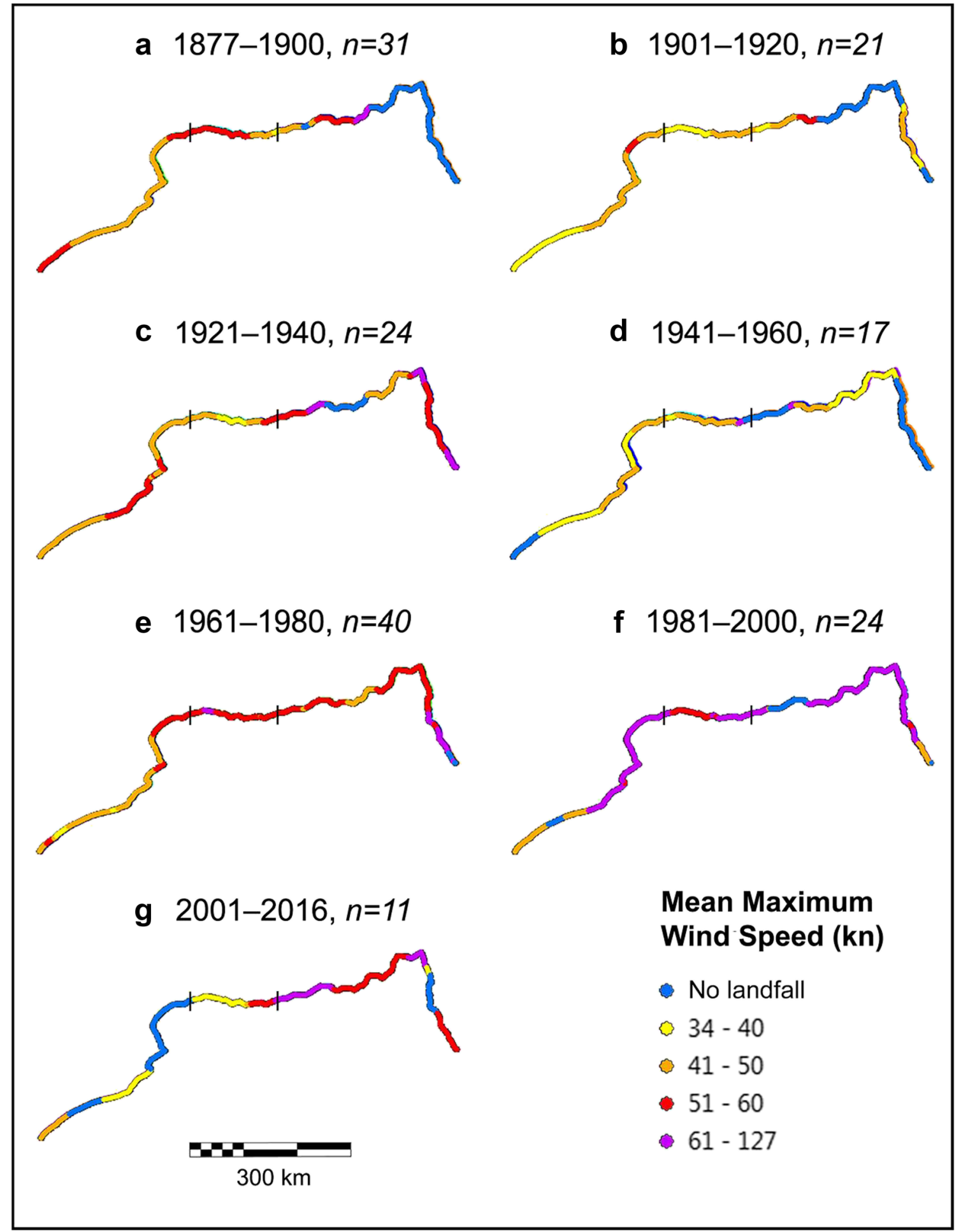

Figure 8 Mean maximum wind speed of cyclones landfalling in the Northern Bay of Bengal coast, shown by periods (a-g), 1877-2016. Data Source: IBTrACS, IMD 


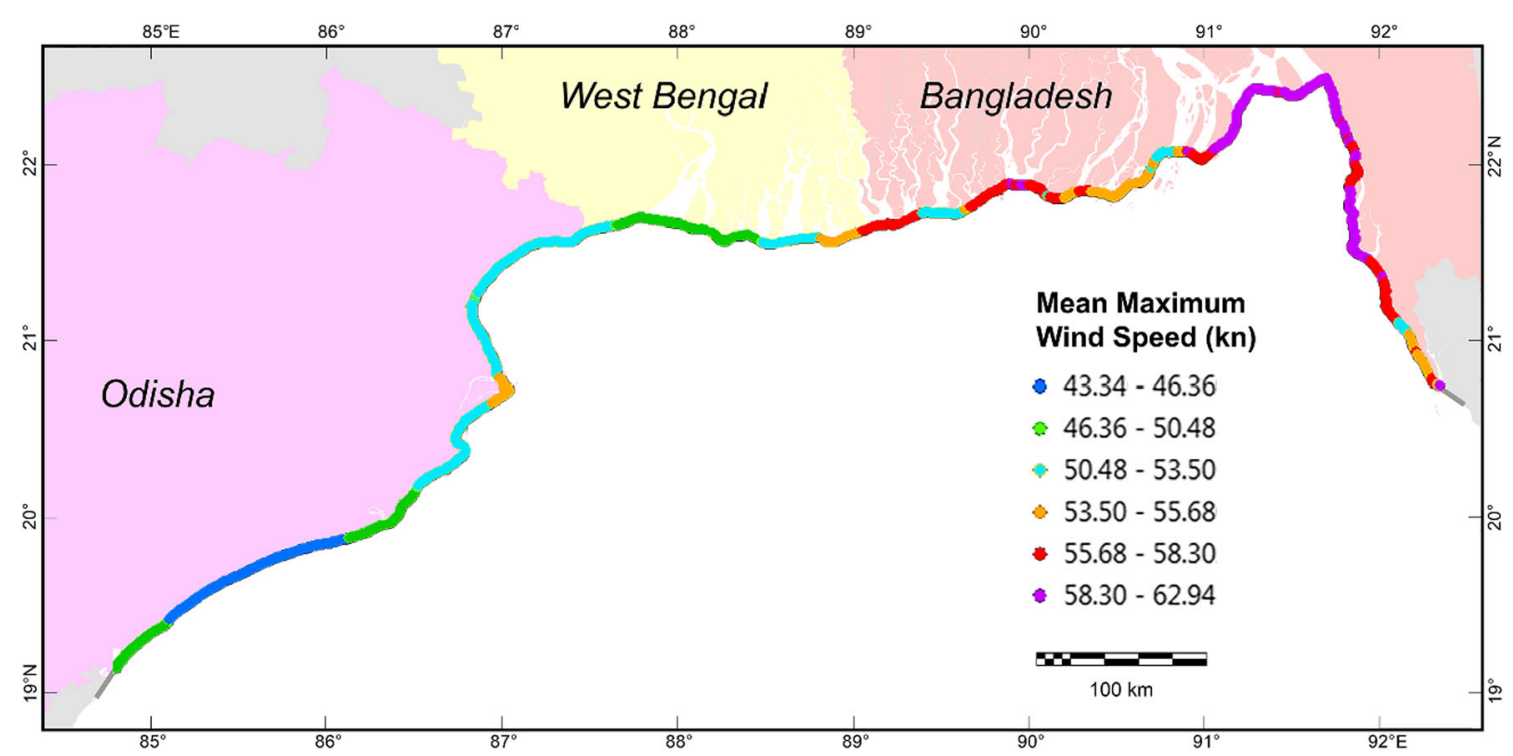

Figure 9 Mean maximum wind speeds of cyclones landfalling in the Northern Bay of Bengal coast, composite for 1877-2016. Data source: IBTrACS, IMD 


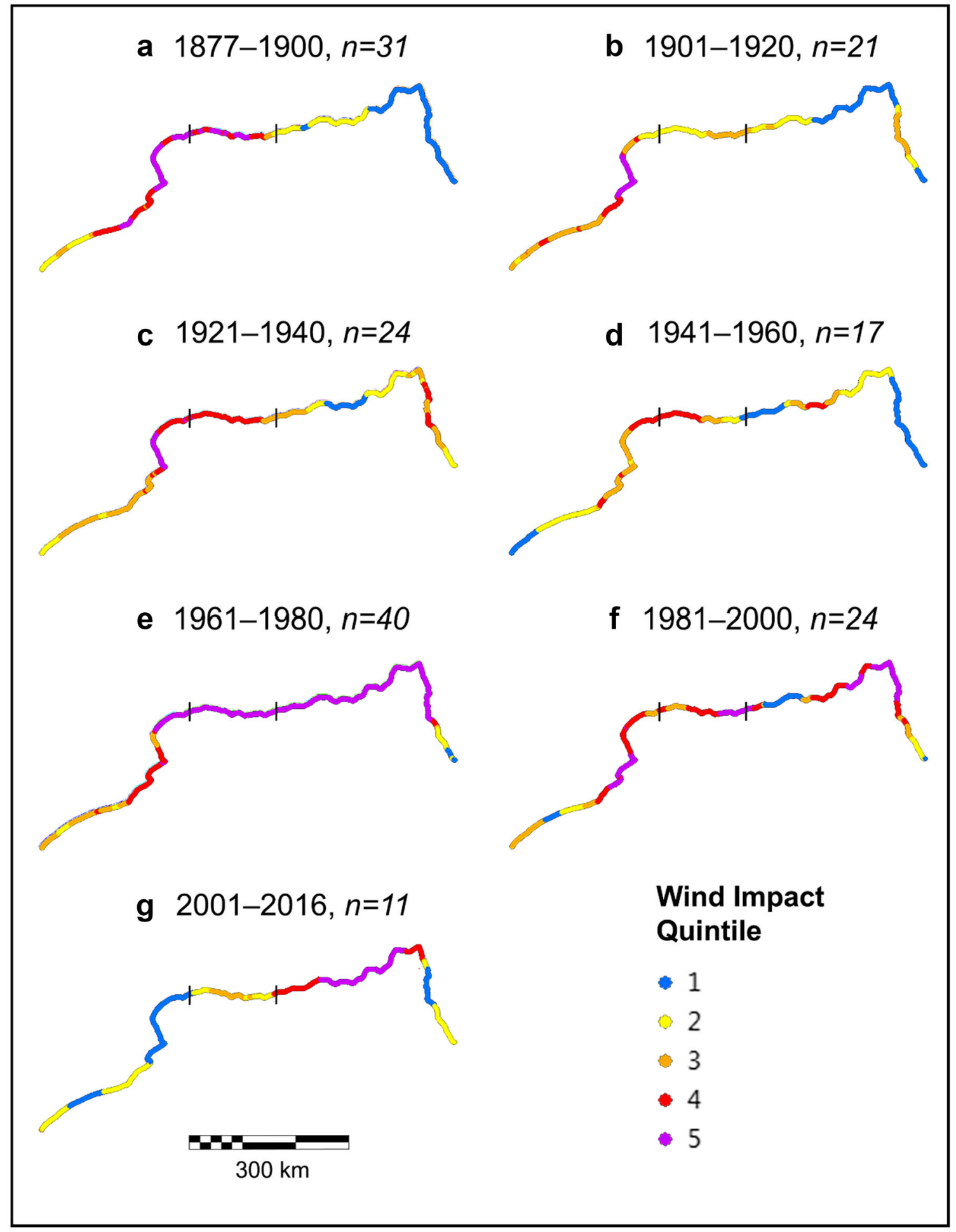

Figure 10 Cyclone impact quintiles, Northern Bay of Bengal coast, shown by periods (a-g). Data Source: IBTrACS, IMD 


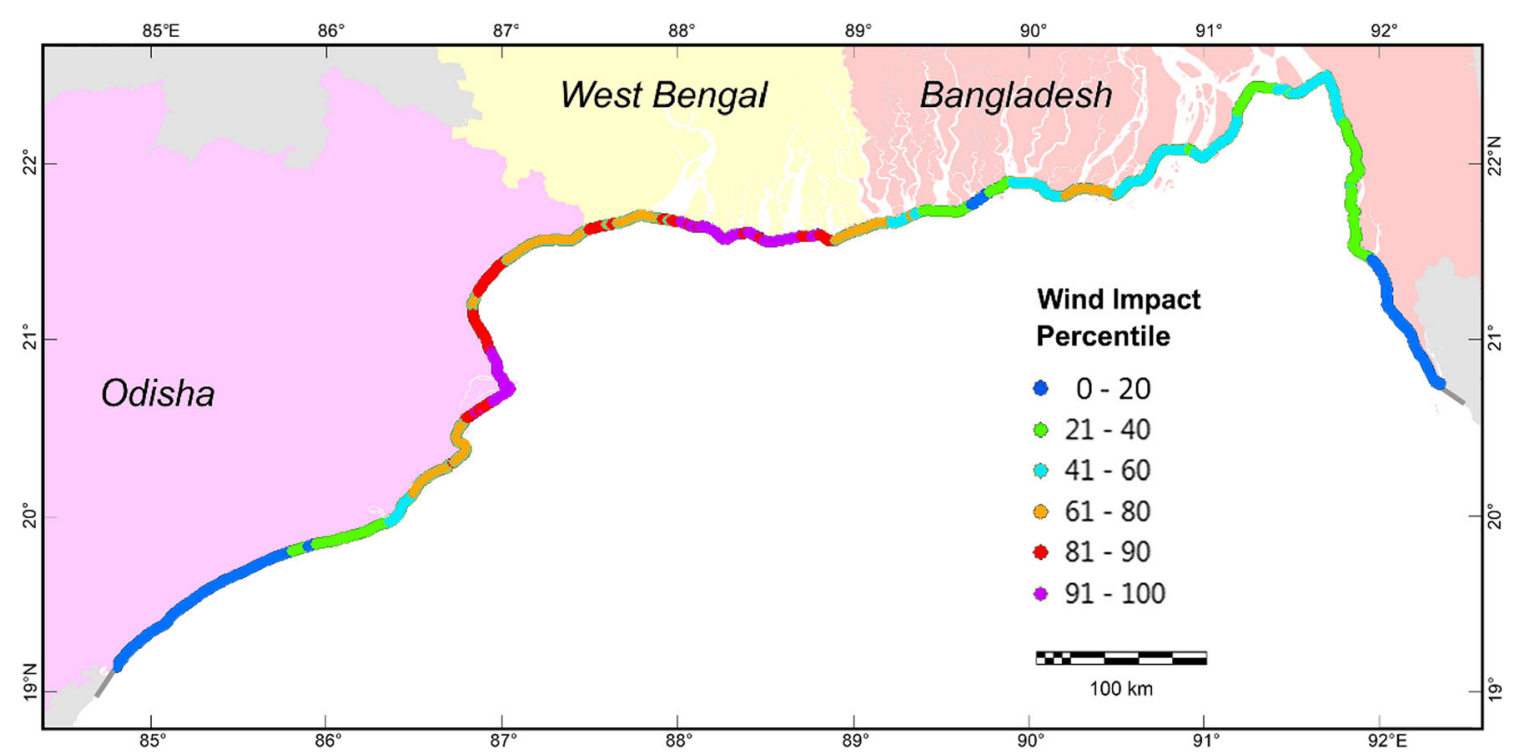

Figure 11 Cyclone impact percentiles, Northern Bay of Bengal coast, composite for 1877-2016. Data source: IBTrACS, IMD

The original article has been corrected.
Publisher's Note Springer Nature remains neutral with regard to jurisdictional claims in published maps and institutional affiliations. 